Geografia e Ordenamento do Território, Revista Electrónica

Centro de Estudos de Geografia e Ordenamento do Território

http://cegot.org

ISSN :2182-1267

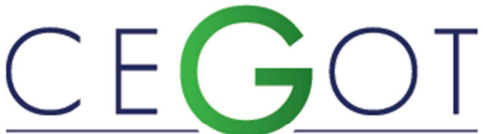

Centro de Estudos de Geografia e Ordenamento do Território
Covas, António

Centro de Investigação sobre o Espaço e as Organizações (CIEO), Universidade do Algarve, Faculdade de Economia Edifício 9, Campus de Gambelas, 8005-139 Faro, Portugal acovas@ualg.pt

Covas, Maria

Centro de Investigação sobre o Espaço e as Organizações (CIEO), Universidade do Algarve, Faculdade de Economia 8005-139 Faro, Portugal mcovas@ualg.pt

\title{
A dieta mediterrânica - a criação de uma cadeia de valor multifuncional. Para uma nova inteligência territorial no rural tradicional algarvio. Uma abordagem exploratória ${ }^{1}$
}

Referência: Covas, António; Covas, Maria (2015). A dieta mediterrânica - a criação de uma cadeia de valor multifuncional. Para uma nova inteligência territorial no rural tradicional algarvio. Uma abordagem exploratória (GOT), n.o 7 (junho). Centro de Estudos de Geografia e Ordenamento do Território, p. 111-128, dx.doi.org/10.17127/got/2015.7.005

\section{Resumo}

A sociedade da informação e do conhecimento abre-nos a porta para um novo sistema de valores. A esse sistema de valores atribuímos o nome de "sociedade CO", uma sociedade onde as redes inteligentes e colaborativas desempenham um papel fundamental. A apelação Dieta Mediterrânica, Património Imaterial da Humanidade, atribuída pela UNESCO, é uma boa oportunidade para reaprender os processos de desenvolvimento de sociedades ou regiões ditas "tradicionais". A apelação "património imaterial" inverte a ordem estabelecida das cadeias de valor convencionais e coloca a "iconomia" no coração do sistema local de produção. O conceito de cadeia de valor multifuncional dá conta dessa alteração fundamental e a discussão final incide, justamente, sobre o alcance dessa mudança de orientação

Palavras-Chave: Sociedade "Co", redes inteligentes e colaborativas, dieta mediterrânica, iconomia, territórios-rede, cadeia de valor multifuncional.

\footnotetext{
${ }^{1}$ Este texto está escrito de acordo com a antiga ortografia.
} 


\begin{abstract}
The information and knowledge society shows the way for a new value system, a system which can be named as the "Co society" where the collaborative and intelligent networks play an outstanding role. The Mediterranean Diet label, the world immaterial heritage, awarded by UNESCO, is an excellent opportunity to reopen the development process of the so called rural traditional societies. The label "immaterial heritage" reverses the order of the conventional value chain and places the "iconomy" at the heart of the local production system. The concept of multifunctional value chain is well suited for this fundamental shift and therefore the final discussion which opens the debate on this refreshed approach.
\end{abstract}

Keywords: "Co" society, intelligent and collaborative networks, Mediterranean Diet, iconomy, territorial networks, multifunctional value chain.

\title{
1. Introdução
}

Vivemos na sociedade da informação e do conhecimento onde as redes inteligentes e a economia do imaterial desempenham, cada vez mais, um papel decisivo. A apelação Dieta Mediterrânica, que nos foi atribuída pela UNESCO, não é, ainda, um conceito funcional e muito menos um quadro de actuação territorial. Todavia, a apelação "património imaterial da humanidade" encerra um complexo de evocações, intuições, sentimentos e factos simbólicos que, uma vez reagrupados em redor dos conceitos de cadeia de valor e economia das redes, nos pode ajudar a desbravar um caminho muito prometedor para o desenvolvimento de regiões mais desfavorecidas. Em grande medida, a denominação "património imaterial" não só inverte a ordem habitual das cadeias de valor, geralmente de montante para jusante, como nos remete para um "grande movimento de transição" dos territórios onde a economia das redes desempenha um papel crucial e onde a combinação entre recursos materiais e recursos imateriais ocupa um lugar central pela forma como pode recriar uma cadeia de valor multifuncional. A construção de um território-rede para a Dieta Mediterrânica inscreve-se neste grande movimento de transição para a "Sociedade CO". 


\section{O grande movimento de transição para a "Sociedade CO"}

Na sociedade da informação e do conhecimento, a emergência, lenta mas sustentada, de uma cultura digital e colaborativa é um sinal dos tempos e uma evidência irrecusável nas sociedades actuais. Ela começa na inovação tecnológica, passa para as plataformas tecnológicas e redes inteligentes e, em seguida, para as comunidades online e redes sociais diversas que interagem com as comunidades offline e as pessoas concretas que habitam um território em particular. As obras de vários autores, entre elas, as de Jeremy Rifkin (2001, 2014), Joel de Rosnay (2012, 2010, 2008, 2006, 1995), Gonçalo R. Telles, (2011, 2003), Miguel Altieri (2008, 2004), Paul Virilio (1977), Pierre Bourdieu (2013), Zygmunt Bauman (2000), Ulrick Beck (1999, 2002, 2009), U. Beck, Anthony Giddens e Scott Lash (2004), Karl Polanyi (2000, 1944), Michel Certeau (1990), Mancur Olson (1999), Joan Martinéz Alier (2007), António Covas e Mercês Covas (2014, 2014a, 2013, 2012, 2011), entre outros, alertam-nos, cada uma a seu tempo e a seu modo, para os sinais emergentes de uma sociedade mais "liquida, fluida e reticular". Quer dizer, no seio da sociedade da informação e do conhecimento, nesse novo caldo de cultura, nasce progressivamente a "Sociedade Co", um grande movimento societal e social em redor dos valores do conhecimento, colaboração, comunidade, comunicação, comunhão, confiança, convivialidade e congratulação. Vejamos, neste contexto em transição, como se apresentam os candidatos a territórios-rede (T-R) que queremos construir tendo como pano de fundo a obra Os territórios-Rede (Covas e Covas, 2014), onde os autores fazem um primeiro balanço dos requisitos necessários para ser território-rede.

\section{Os territórios são cada vez menos um stock e cada vez mais um fluxo.}

Por isso, não devem ser pensados exclusivamente de "dentro para dentro", como até aqui, mas de "dentro para fora" e de "fora para dentro". Enquanto fluxos os Territórios-Rede são, simultaneamente, comunidades online e offline, isto é, o campo das suas possibilidades está para lá dos seus limites e fronteiras e é esse "campo de compossibilidade" que define os territórios-rede como espaços de construção de arranjos colaborativos. 


\section{Os territórios parecem sofrer do paradoxo da cooperação entre vizinhos.}

O paradoxo da cooperação é visível na baixa interacção/intensidade das redes convencionais de vizinhança e pode ser descrito desta forma: a cooperação entre vizinhos e entre interesses semelhantes é mais superficial e corporativa por comparação com a cooperação dissemelhante ou complementar que é mais intensa e colaborativa; ora, o Território-Rede, como nós o entendemos, pertence a esta segunda categoria (Covas e Covas, 2014).

A cooperação social não é um produto virtuoso de circunstâncias especialmente favoráveis ou uma característica ou atributo dos actores em presença.

A cooperação territorial é mais processo e procedimento do que output e input no jogo de forças entre grupos sociais para moldar as regras do jogo à sua vontade; ao interferir directamente na formação dos significados em torno dos quais se organiza a acção, a regulação do processo de cooperação exige especiais competências ao actor-rede, o pivot do território-rede.

\section{A grande questão dos Territórios-Rede é a forma e o processo de ligação entre} recursos tangíveis e recursos intangíveis.

A grande questão já não são as velhas polarizações, dicotomias, binómios, dualidades, (entre rural e urbano, entre moderno e tradicional, entre cidade e campo); a grande questão dos T-R é despertar a inteligência colectiva do território e criar uma economia colaborativa onde as comunidades virtuais estejam ao serviço da comunidade e da economia reais; estamos a falar do Paradigma da Iconomia feito de internet, informação, inteligência, inovação, imaterial e intangível. 
No plano metodológico e operativo, os T-R têm a obrigação de conhecer a distinção entre territórios normativos e territórios cognitivos.

Os territórios, tal como os conhecemos e praticamos, estão muito assentes no problemsolving e na policy, isto é, são mais normativistas; pelo contrário, os territórios cognitivos assentam mais no problem-saving, ou seja, numa abordagem assente mais na politics e na polity. Os T-R e o actor-rede que os administra têm de possuir a sabedoria de uma dosagem apropriada entre factores normativos e factores cognitivos.

\section{Os T-R serão o instrumento de uma economia criativa e colaborativa com um} suporte avançado na cultura digital.

A "cooperação dissemelhante" de geometria variável promovida pelos T-R pode mobilizar de forma criativa e colaborativa os recursos imateriais e intangíveis que valorizam muito o cabaz de produtos de uma região; doravante, passaremos a ouvir falar mais de sharing economy, crowd economy, peer to peer production, collaborative commons, territorial networking, moedas criativas e sociais, internet das coisas, etc.

Estes atributos fazem parte do movimento de transição para a "Sociedade CO" que, de forma muito esquemática, se apresenta na Figura 1.

Figura 1 - A transição para a Sociedade "CO"

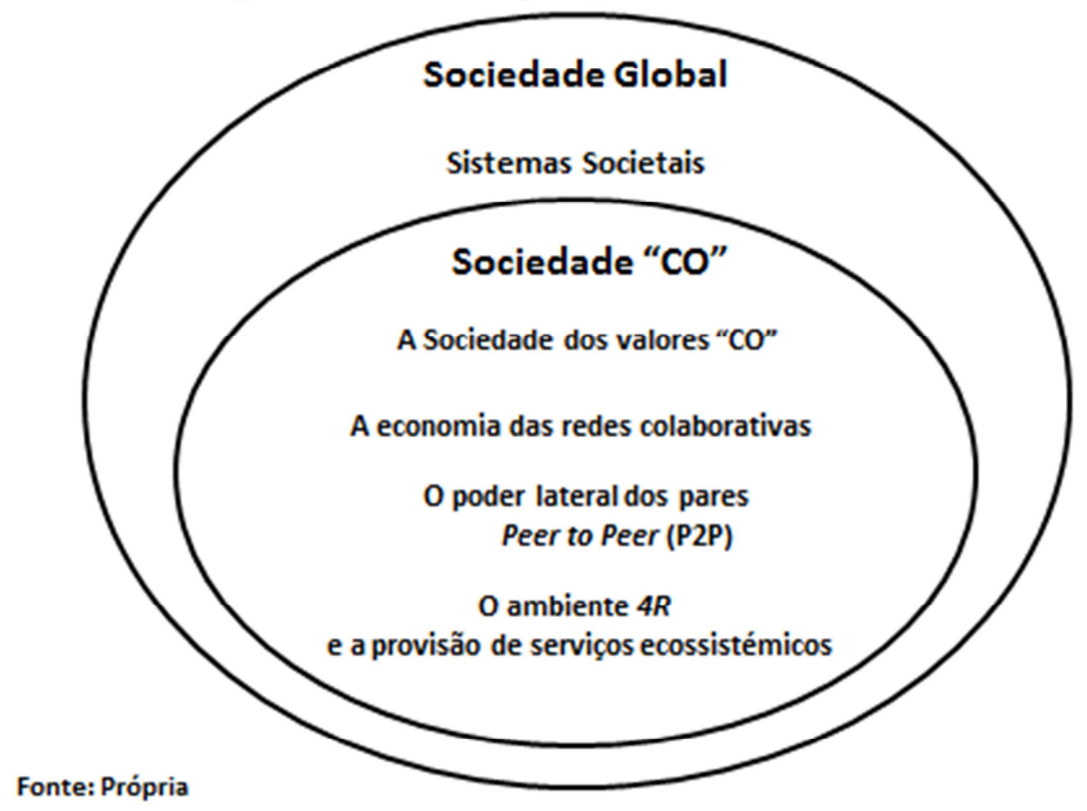


Acreditamos que a transição para a "Sociedade CO" é o enquadramento adequado para o desenvolvimento da Dieta Mediterrânica, em toda a sua densidade e complexidade, material e imaterial, em especial pelo modo como entende a formação da cadeia de valor. Com efeito, estamos habituados a cadeias de valor do tipo "silo", completamente verticalizadas e debaixo de um complexo de relação de forças que, com frequência, produz externalidades negativas sobre o ambiente e o território e esmaga margens comerciais já reduzidas de pequenos produtores. Por isso, a criação de uma cadeia de valor multifuncional que seja a expressão da utilidade social do respeito interpares, assente em valores e redes colaborativos e numa economia circular 4R (redução, reparação, reciclagem e reutilização) de produção conjunta de bens agro-industriais e serviços ecossistémicos remunerados, é um imperativo de sociedade e cultura que a Dieta Mediterrânica deverá observar como veremos mais adiante.

\section{Dieta Mediterrânica, uma apelação imaterial de prestígio}

A Dieta Mediterrânica, recentemente proclamada património imaterial da humanidade pela UNESCO, foi uma candidatura transnacional de sete países (Portugal, Espanha, Itália Grécia, Chipre, Croácia e Marrocos) liderada pela cidade algarvia de Tavira. A aprovação recente desta candidatura em Dezembro de 2013 é uma excelente ocasião para provar a pertinência da construção social de um território-rede que seja a retaguarda e o suporte territorial desta prestigiada apelação internacional e que funcione como um laboratório de ensaio de muitas especificações contidas nesta denominação territorial.

\subsection{Dieta Mediterrânica, uma apelação territorial de prestígio.}

A Dieta Mediterrânica é uma construção social e cultural milenar. Desde sempre, o homem mediterrânico necessitou de todo o seu engenho e arte para lutar contra a escassez de água e alimentos. É deste relacionamento intenso e através desta aprendizagem constante que se vão modelar os hábitos alimentares dos diferentes povos desta região. A dieta mediterrânica é, portanto, uma cultura alimentar adaptada à escassez, é um modo de 
produção e conservação de alimentos ajustado a uma natureza hostil, é, finalmente, um modo de viver a vida, pela sua convivialidade e especial sociabilidade.

No artigo $2 \%$ da Convenção da UNESCO sobre património cultural imaterial pode ler-se:

1. Entende-se por "património cultural imaterial" as práticas, representações, expressões, conhecimentos e aptidões - bem como os instrumentos, objectos, artefactos e espaços culturais que lhes estão associados - que as comunidades, os grupos e, sendo o caso, os indivíduos reconheçam como fazendo parte integrante do seu património cultural. Esse património cultural imaterial, transmitido de geração em geração, é constantemente recriado pelas comunidades e grupos em função do seu meio, da sua interacção com a natureza e da sua história, incutindoIhes um sentimento de identidade e de continuidade, contribuindo, desse modo, para a promoção do respeito pela diversidade cultural e pela criatividade humana. Para os efeitos da presente Convenção, tomar-se-á em consideração apenas o património cultural imaterial que seja compatível com os instrumentos internacionais existentes em matéria de direitos do homem, bem como com as exigências de respeito mútuo entre comunidades, grupos e indivíduos.

2. O "património cultural imaterial", tal como definido no número anterior, manifesta-se nomeadamente nos seguintes domínios:

a) Tradições e expressões orais, incluindo a língua como vector do património cultural imaterial;

b) Artes do espectáculo;

c) Práticas sociais, rituais e eventos festivos;

d) Conhecimentos e práticas relacionadas com a natureza e o universo;

e) Aptidões ligadas ao artesanato tradicional.

3. Entende-se por "salvaguarda" as medidas que visem assegurar a viabilidade do património cultural imaterial, incluindo a identificação, documentação, pesquisa, preservação, protecção, promoção, valorização, transmissão, essencialmente através da educação formal e não formal, bem como a revitalização dos diferentes aspectos desse património.

Como se pode observar, as definições da Convenção reportam-se a um conceito de património imaterial que não se reduz a um mero acto conservacionista. Estamos a falar de um património imaterial que poderíamos designar de comunitário ou comunitarista, um património do quotidiano e, como tal, um património dinâmico, criativo e em permanente mutação. Todavia, esta perspectiva abrangente do património imaterial levanta sérias questões científicas, técnicas, processuais e procedimentais que colocarão grandes dificuldades ao trabalho de intermediação e cooperação da própria UNESCO, em especial, a harmonização mínima necessária a uma base comum de inventariação e classificação dos bens e serviços culturais e patrimoniais.

De acordo, ainda, com a decisão da UNESCO de Dezembro de 2013:

A dieta mediterrânica envolve uma série de competências, conhecimentos, rituais, símbolos e tradições ligadas às colheitas, à safra, à pesca, à pecuária, à conservação, processamento, confecção e, em particular, à partilha, à convivialidade e ao consumo dos alimentos. Comer em conjunto é a base da identidade cultural e da sobrevivência das comunidades por toda a bacia do Mediterrâneo. 
Numa entrevista de Samuel Silva a Pedro Graça, no Jornal Público, em 4/12/2014, "Alimentação desequilibrada tem impacto negativo no rendimento escolar dos estudantes" (Graça, 2014), pode ler-se:

\begin{abstract}
... Assim, não é de estranhar a referência constante à recolecção de produtos silvestres (os caracóis, moluscos, cogumelos), a tradição na recolha de produtos vegetais selvagens (beldroegas, espargos e agriões), o estatuto da caça, a existência de uma enorme tradição de pastoreio para fornecer a proteína animal e o recurso a alimentos sazonais frescos ou conservados que forneciam a energia necessária quando faltavam as outras fontes de energia (figos secos, amêndoas, grão, favas e outras leguminosas, alfarroba, bolotas, etc.) (Graça, 2014).
\end{abstract}

... Esta constante adaptação à escassez está na origem de uma arte culinária muito rica que é, afinal, um desafio vegetariano à escassez de proteína animal. Devido às temperaturas elevadas, a arte culinária do mediterrâneo utiliza a cozedura com frequência nas sopas, ensopados, estufados, jardineiras e caldeiradas. Outra forma de reduzir a contaminação dos frescos e das saladas é através da utilização frequente de substâncias ácidas como o vinagre, o limão ou a laranja amarga. Nas bebidas, o vinho, simples ou traçado, tem o equivalente no chá de hortelã ou de outras ervas aromáticas do sul da bacia mediterrânica. Nas carnes e no pescado o sal é o conservante. Nas frutas é a presença do açúcar e do mel que funcionam como conservante (Graça, 2014).

Estamos na região do Algarve, sede da candidatura à UNESCO através da cidade de Tavira. Entretanto, o ano 2014 foi considerado o Ano Internacional da Agricultura Familiar. A associação íntima entre a promoção da Dieta Mediterrânica e o relançamento da agricultura familiar levanta-nos as seguintes interrogações:

Como é que a apelação "património imaterial da humanidade", proveniente de uma organização internacional como a UNESCO, pode aproveitar à agricultura familiar e promover as pequenas economias locais da região algarvia?

Como é que as especificações e o plano de salvaguarda desta certificação internacional podem ajudar a modernizar e a promover a agricultura familiar e as pequenas economias da região do Algarve sem as segregar ou excluir?

Que estratégias, regional e multilocal, podemos desenhar para levar a cabo a "grande aliança" entre educação para a saúde alimentar, o desenvolvimento da agricultura familiar e das pequenas economias locais do interior e a promoção do património imaterial das suas culturas respectivas? 
Como proceder, desde já, para evitar que a erosão do padrão alimentar da dieta mediterrânica se acentue, que uma apelação internacional de prestígio seja trocada, com ligeireza, por festivais de culinária mediterrânica, que as economias locais e a agricultura familiar sejam abandonadas à sua sorte e os pequenos aglomerados do interior desertificados, que as culturas locais sejam abastardadas ainda mais dando lugar ao mau gosto e ao kitch mediterrânico para "turista ver"?

\subsection{Dieta Mediterrânica, uma promessa de futuro.}

Para lá dos aspectos mais utilitários, produtivos e comerciais, a classificação de património imaterial da humanidade é, antes de mais, uma promessa de futuro para uma região, o Algarve, se quisermos, um crédito por conta do que falta fazer na região se, para tanto, seguirmos o caderno de encargos e especificações que acompanha a classificação atribuída. A Dieta Mediterrânica é, digamos, um conceito que atravessa a região em toda a sua extensão, do património imaterial como representação simbólica até ao património material como suporte da dieta mediterrânica. É preciso, pois, perceber que não se trata de duas realidades distintas, mas de duas faces da mesma realidade e que preservar o património imaterial equivale a conservar e desenvolver o património material.

Este registo e esta exigência são tanto mais importantes quanto sabemos que, em nome do progresso económico e social, se observam, com frequência, ocorrências preocupantes: uma edificação dispersa recorta o território de forma desordenada e degrada a utilização do capital fundiário; o poder de controlo do capital imobiliário afecta a conservação e o uso múltiplo do capital natural; uma intensificação técnica e tecnológica empobrece os atributos biofísicos dos ecossistemas e do território, ao mesmo tempo que reduz a provisão de serviços ambientais na região. No final, a crescente velocidade de rotação do capital financeiro acaba por entrar em rota de colisão com os ritmos de regeneração própria dos sistemas biofísicos. É preciso que nos preocupemos mais com a temporalidade das tecnologias porque o planeta não está em condições de ser indefinidamente reconstituído pelos ritmos que elas impõem.

A Dieta Mediterrânica, como promessa de futuro, é a expressão cultural e simbólica de um equilíbrio delicado entre a natureza e a actividade humana, que o tempo porfiou e o 
homem confiou. No cerne da questão, em nome do progresso e da tecnologia, teremos a disseminação de monoculturas, a monotonia biofísica e a redução da diversidade social, as diversas facetas do mesmo problema. A cada velocidade a sua cultura. Ora, a Dieta Mediterrânica precisa, com alguma urgência, de um plano de preservação que a proteja dos "riscos morais" de curto prazo, pois há sempre alguém disposta a sacrificá-la no altar da hipervelocidade e do consumo indiscriminado.

A Dieta Mediterrânica tem aqui um dos seus maiores desafios. Depois da biopolítica do século XX feita de limpeza, higiene, rastreabilidade e certificação, na biopolítica do século XXI a engenharia genética e a biotecnologia molecular, as terapias genéticas mas, também, os alimentos nutricêuticos, a bioética e os novos códigos da vida, adquirem uma condição política elevada. Ao mesmo tempo, a natureza é um imenso campo de possibilidades de manipulação à nossa disposição. O mundo natural e biológico torna-se, portanto, um universo cultural, isto é, pode ser produzido e reproduzido. Cuidado, pois, com a diversidade de biologias de acordo com diferentes programas de investigação, cuidado, pois, com a domesticação de plantas e animais, cuidado, pois, com a fabricação da vida por via de alimentos, fármacos e intervenções de inspiração muito diversa.

Neste contexto, que lugar pode ocupar a Dieta Mediterrânica? Uma presa fácil da política de velocidade e das tecnologias de substituição, um local de refúgio para os mais avisados, ou, um estilo de vida e um padrão alimentar geralmente aceites pela população? Escapará a dieta mediterrânica à política de normalização do capitalismo actual que visa transformarnos a todos numa espécie de "proletários do sistema capitalista em modo monocultural"?

O capitalismo está, por razões imanentes ao seu funcionamento, obrigado a criar permanentemente novas oportunidades de negócio. A Dieta Mediterrânica pode emergir, portanto, como mais uma oportunidade de negócio interessante. Neste contexto, a dieta mediterrânica pode já estar, sem o saber, em rota de colisão com o capitalismo regional e internacional. Ela é uma espécie de contracultura e contra-racionalidade, em luta muito desigual contra o "regime estabelecido" que, entretanto, aproveita para fazer o elogio público de "uma nova promessa" de desenvolvimento regional.

A atribuição desta apelação internacional pela UNESCO é, pois, um desafio muito interessante para a "sociologia política local e regional" e, nesse sentido, ninguém aprovaria que a dieta mediterrânica fosse conhecida como a história de uma captura e de uma 
enorme dissimulação, por mais sucesso e brilhantismo de que a operação fosse coroada. Resta, então, a possibilidade que todos aguardam, a saber, a Dieta Mediterrânica como o exemplo eloquente de uma produção social de qualidade, que melhora o bem-estar material das populações locais e valoriza o património material em que assenta, justificando, dessa forma, a apelação internacional que lhe foi concedida. Este é o desafio que temos pela frente, um desafio para uma nova inteligência territorial no rural tradicional algarvio.

\section{A formação da cadeia de valor multifuncional do território- rede da Dieta Mediterrânica}

Se a dieta mediterrânica, pelo valor potencial que encerra, é uma promessa de futuro, então a nossa pergunta de partida é a seguinte: como fazer a conversão de uma "expectativa positiva", a Dieta Mediterrânica, num processo participativo de sucesso e numa produção social de qualidade e como operar essa conversão através de uma cadeia de valor que liga um património imaterial da Humanidade a um património material regional, de tal modo que pode transformar, de forma relevante, a estrutura económica, social e empresarial de uma comunidade ou região? (Covas e Covas, 2014: 204).

\subsection{Uma produção social de qualidade.}

Sabemos que a produção de qualidade não existe em abstracto e duas abordagens são possíveis. Na primeira, o "mercado sabe" melhor do que ninguém o que o cliente precisa. Mercado e cliente, duas noções abstractas ao serviço de uma "ideologia da qualidade". Na segunda, a qualidade é um atributo que pode ser negociado por sucessivas "convenções ou regras de procedimento", desde a produção até ao consumo e num processo interactivo e negocial em que estão implicados diversos actores com estratégias diferenciadas. O que se pretende é que a qualidade passe a ser o resultado de um consenso social e de um processo de aprendizagem com implicações políticas e organizacionais, no sentido em que existem e 
são reconhecidos diversos modos alternativos de "produzir socialmente qualidade" (Covas e Covas, 2014: 205).

Sabemos já que a economia de mercado, ela própria, usa inúmeras convenções ou regras, desde as normas técnicas às marcas e certificações, já para não falar do próprio mecanismo de preços. Também sabemos que estas regras e procedimentos convencionais já não são suficientes para assegurar a qualidade e a tranquilidade dos consumidores. A pergunta que se impõe é a seguinte: pode a Dieta Mediterrânica estar na origem de uma "economia convencional emergente", de um "inovador sistema produtivo local", de um "território-rede de alto valor acrescentado" com base em mercados de proximidade e circuitos curtos, mas, também, em relações interpessoais e nos valores e princípios de uma economia solidária e colaborativa? (Covas e Covas, 2014: 205).

Ou, ainda, ao criar uma "contra-racionalidade socio-territorial protegida" por uma apelação internacional de prestígio, pode a Dieta Mediterrânica estar na origem de um contra ou alter-movimento local e regional que alargue o campo de possibilidades do território e estenda a "produção social de qualidade" para outras áreas de produção e consumo que até aí estavam quase blindadas pela "ordem local" do capitalismo reinante? (Covas e Covas, 2014: 205).

A produção e o consumo são sempre localizados e realizados por produtores e consumidores concretos em algum lugar, o que permite estabelecer convenções ou procedimentos sempre que a qualidade seja considerada um "bem comum" repartido e baseado na confiança mútua. Neste sentido, a "produção social de qualidade" pode ser usada para promover uma estratégia de desenvolvimento rural, feita de uma pluralidade de agriculturas com base em produtos tradicionais de alto valor biológico, ecossistémico e paisagístico. Evidentemente, levamos em conta o arsenal disponível no local como sejam as indicações geográficas, denominações, marcas colectivas, selos, etiquetas, de processo e qualidade, que, elas também, podem ser objecto de negociação e convenção. (Covas e Covas, 2014: 205).

Em síntese, uma "produção social de qualidade" pode e deve ser um excelente pretexto, não apenas para rever os programas de desenvolvimento, investigação e extensão agrorurais, mas, sobretudo, para relançar a economia e a sociedade locais. A Dieta Mediterrânica é um excelente pretexto para inovar localmente em matéria de inteligência territorial, por intermédio do instrumento "economia das convenções", um pacto territorial 
para dar à luz um sistema agro-alimentar local e uma cultura simbólica assertiva que respeitem e valorizem a apelação de prestígio internacional que Ihe foi concedida (Covas e Covas, 2014: 206).

\subsection{A formação da cadeia de valor multifuncional.}

A formação da cadeia de valor da dieta mediterrânica deverá ocorrer na zona de interface entre a economia dos agroecossistemas, a montante, a economia do imaterial e do simbólico, a jusante, e a economia do lazer e da visitação em vários pontos da cadeia. $\mathrm{Na}$ Figura 2 o "silo vertical" próprio das cadeias agro-industriais convencionais, com produção de externalidades positivas e negativas em todas as direcções, dá lugar a uma economia circular de redes inteligentes e colaborativas (bens comuns colaborativos) em que as externalidades e internalidades são uma "produção conjunta" do território-rede que estamos a considerar.

Figura 2 - Cadeia de Valor Multifuncional A Produção Conjunta de Externalidades e Internalidades Positivas

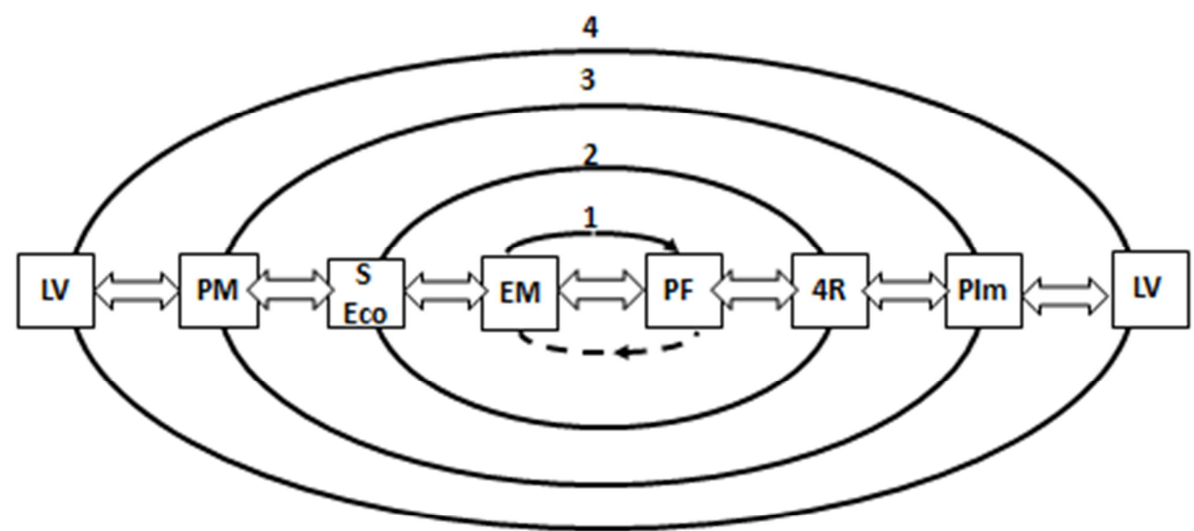

Legende:

EM - Energio e Matéria; LV - Lazer e Visiteção; PM - Património Material; Plm - Património Imaterial;

PF-Produtos Finais; SEco - Senviços Ecossistémicos; 4R - Reduçẽo, Repareção, Reciclogem e Reutilizeção.

1 - Ciclo Agro-industrial Convencional (unidirecional); 2 - Cielo Ecossistémico (circular e bidirecional);

3 - Ciclo Patrimonial (o memória e o simbólico); 4-Ciclo do Lazer e da Visitação.

Fonte: Própria

A título de exemplo, pensemos na verticalização da cadeia de valor da cabra algarvia e nas tarefas que essa opção acarreta, sempre numa perspectiva de valorização das economias locais e dos seus ecossistemas mais sensíveis, lá onde a cabra algarvia tem o seu nicho ecológico preferido (quem diz cabra diz mel, medronho, frutos silvestres, pomar tradicional de sequeiro, citrinos, flores, cogumelos, cortiça, caça, etc.). 
No que diz respeito às tarefas a realizar, a verticalização da cadeia de valor exige:

- Em primeiro lugar, trata-se de reagrupar os produtores da raça autóctone da cabra algarvia tendo em vista apurar e valorizar a biodiversidade local da espécie e do seu nicho ecológico;

- Em segundo lugar, trata-se de organizar a assistência técnica, associativa e pública, nessa linha de abordagem mais agroecológica e ecossistémica;

- Em terceiro lugar, trata-se de rejuvenescer o capital social envolvido, seja no plano familiar dos produtores, seja convidando "novas entradas" para o agrupamento;

- Em quarto lugar, trata-se de melhorar o processo de produção, de alargar as funções da cadeia de valor e de acrescentar as suas internalidades tendo em vista reduzir os seus custos de transacção internos: raça, pastagem, biodiversidade, limpeza de matos, compostagem, etc.;

- Em quinto lugar, trata-se de diversificar a linha de produtos finais da cabra algarvia e de diversificar os mercados-alvo por via de uma comercialização e marketing mais inteligentes;

- Finalmente, trata-se de capitalizar a fileira de produção e de articular a cadeia de valor da cabra algarvia com a exploração florestal das zonas de intervenção florestal (ZIF), acrescentando, por essa via, a massa, o músculo e o sistema nervoso deste sistema produtivo local regional.

Porém, esta metodologia multissectorial para a verticalização da fileira da cabra algarvia só será inteiramente bem-sucedida se, ao mesmo tempo, tivermos em mãos um projecto de território-rede em construção, inspirado nos princípios de desenvolvimento territorial que sustentam a filosofia da Dieta Mediterrânica. Nesta segunda linha de actuação, mais circular, estamos a robustecer a ecosocioeconomia rural e local e a estruturar as áreas de trabalho que, em si mesmas, constituem o tecido privilegiado para a formação das redes colaborativas e as amenidades locais:

- O alargamento das áreas da agroecologia e da agricultura biológica;

- O alargamento das actividades criativas e culturais, desde as artes culinária e gastronómica, à artesania tradicional, os materiais locais e as oficinas de artes e ofícios;

- A consideração das artes da paisagem e da terra associadas ao turismo de natureza mas, também, à provisão dos serviços ecossistémicos; 
- O desenvolvimento dos produtos e serviços turísticos nas tipologias do turismo de saúde e bem-estar para a sociedade sénior;

- O desenvolvimento das actividades de ecodesign, associadas à economia verde e às artes dos 4R, (redução, reparação, reciclagem e reutilização);

- A promoção das artes do lazer e do recreio, dos espaços pedagógicos, lúdicos e terapêuticos, por exemplo, para a sociedade sénior, onde se incluem os campos de férias e as residências seniores;

- O desenvolvimento das artes multimédia e performativas e a criação de residências artísticas e culturais, assim como os eventos ligados à história local, a literatura oral, a poesia, as paisagens literárias, etc.

Para serem bem-sucedidas, todas estas actividades podem e devem ser objecto de uma "convenção territorial" que passará a ser a lei fundamental da construção social do futuro território-rede (Covas e Covas, 2014). Esta abordagem da cadeia de valor multifuncional exige, porém, uma "ecologia institucional e comunitária" muito complexa, sobretudo no que diz respeito à constituição do actor-rede (Covas e Covas, 2014: 179-184).

\section{Discussão e Conclusões}

Voltamos aqui à emergência dos valores da "Sociedade CO" inicialmente referidos. Desde logo, no plano local, municipal e intermunicipal. A este nível, esta nova ecologia institucional das redes inteligentes e colaborativas faz exigências muito rigorosas. Assim, no futuro próximo, iremos, muito provavelmente, revisitar o conceito de "poder autárquico" no sentido de um poder mais lateral e colaborativo, de um par inter pares, agindo, simultaneamente, em comunidades reais, em plataformas digitais, redes sociais e comunidades online. Esta abertura aumentará o espaço de liberdade e o campo das possibilidades e soluções do município do século XXI, em direcção à composição de territórios-rede de geometria mais variável. Teremos, assim, um município "sem fronteiras" e mais cosmopolita, mais interactivo com os seus concidadãos, com mais economia verde e economia azul, mais criativo e cultural, menos fiscalista e mais contratualista no plano 
financeiro. Em consequência, a sua organização interna e a sua gestão sofrerão uma "pequena revolução", não apenas na estrutura orgânico-funcional e na relação entre o back office e o front office mas, sobretudo, na sua cultura digital e colaborativa, isto é, na estratégia de informação, comunicação e interacção face às redes colaborativas de que fará parte e que, doravante, constituirão o seu novo ecossistema institucional de acolhimento.

No plano do desenvolvimento territorial, esta nova ecologia institucional e comunitária dos territórios-rede faz, igualmente, muitas exigências. Diz respeito, em primeiro lugar, à aprendizagem da cultura digital e colaborativa, logo, à capacitação de comunidades cognitivas de autogoverno e autogestão e de clubes de produtores e consumidores; diz respeito, também, a mercados solidários e sociais, à criação de moedas paralelas, à interacção de comunidades online e offline, à formação de mercados de trabalho para lá dos "mercados oficiais do emprego", à formação de amenidades em íntima articulação com a provisão de serviços ecossistémicos, finalmente, à formação de actividades criativas e culturais a coroar todo o edifício do território-rede.

Em conclusão, a apelação "Dieta Mediterrânica, património imaterial da humanidade" afigura-se como uma oportunidade única para realizar o up-grade da economia local e regional algarvia, em especial a promoção da economia do barrocal algarvio e da economia serrana. Esta conviç̧ão deve, porém, conter uma expectativa contida e moderada. Para o efeito, a região precisa urgentemente, no plano da microgeoeconomia territorial e dos territórios-rede, de levar a cabo um ensaio experimental, uma rede temática e territorial, que possa lançar as primeiras sementes do que será, no futuro próximo, uma política de certificação regional da dieta mediterrânica. Este é um desafio de longo alcance e um bem comum inestimável para o país e a região do Algarve. Os valores culturais, patrimoniais, naturais e paisagísticos do mundo rural são um bem público inestimável cuja fragilidade e vulnerabilidade importa contrariar a todo o custo. A desertificação, as secas prolongadas, os incêndios florestais, a degradação das reservas naturais de futuro, são uma ferida a céu aberto nos ecossistemas agro-rurais da região do Algarve. Até que ponto, o sistema produtivo local e as cadeias de valor da Dieta Mediterrânica poderão contribuir para mitigar e contrariar os riscos climáticos e ambientais associados a um despovoamento destes territórios? Fica a interrogação. 


\section{Referências}

AAVV, Mediterra (2012). La diète Méditerranéenne pour un dévelopement régional durable. CIHEAM.

ALIER, J. M. (2007). O ecologismo dos pobres. S. Paulo. Editora Contexto.

ALTIERI, M. (2008). Agroecologia, a dinâmica produtiva da agricultura sustentável. Porto Alegre. Editora UFRGS ( 5 a edição).

ALTIERI, M. (2004). Agroecologia. Porto Alegre. Editora UFRGS (4a edição).

BARROS, V. (2014). Dieta Mediterrânica e desenvolvimento rural. Lisboa. ANIMAR Edições.

BOURDIEU, P. (2013). Une revolution symbolique. Paris. Seuil.

BAUMAN, Z. (2000). Liquide modernity. Cambridge. Cambridge Polity Press.

BECK, U. (2009). World at risk,. Cambridge. Cambridge Polity Press.

BECK, U. (2002). Ecological politics in an age at risk. Cambridge. Cambridge Polity Press.

BECK, U. (1999). World risk society. Cambridge. Cambridge Polity Press.

CERTEAU, M. (1990). L'Invention du quotidien. Paris. Gallimard.

COVAS, A. e COVAS, M. (2014). Os territórios-rede, a inteligência territorial da $2^{a}$ ruralidade. Lisboa. Editora Colibri.

COVAS, A. e COVAS, M. (2014a). A construção social dos territórios-rede: a inteligência territorial da $2 \underline{a}$ ruralidade. EBook. Editora Liber Ars.

COVAS, A. e COVAS, M. (2013). A construção social dos territórios-rede da 2a ruralidade: dos territórios-zona aos territórios-rede - construir um território de múltiplas territorialidades. Revista de Geografia $e$ Ordenamento do Território 3: 7-40. (Junho). PDF: 43-66. http://cegot.org/ojs/index.php/GOT/issue/current.

COVAS, A. e COVAS, M. (2012). A caminho da $2^{\underline{a}}$ ruralidade, uma introdução à temática dos sistemas territoriais. Lisboa. Editora Colibri.

COVAS, A. e COVAS, M. (2011). A Grande Transição, pluralidade e diversidade no mundo rural. Lisboa. Editora Colibri.

COVAS, A. e COVAS, M. (2010). Ruralidades V: Modernização ecológica, serviços ecossistémicos e riscos globais. Faro. Edições da Universidade do Algarve.

EC. (2009). Provision of public goods through agriculture in the EU. Institute for European Environmental Policy. UK.

FLIGSTEIN, N. (2012). Theory of fields. Oxford. Oxford University Press.

GRAÇA, P. (2014). "Alimentação desequilibrada tem impacto negativo no rendimento escolar dos estudantes". Público. (4/12/2014).

HAESBAERT, R. (2006). O mito da desterritorialização. Rio de Janeiro. Bertrand Brasil, 2a edição.

HUYLENBROECK, G. and DURAND, G. (2003). Multifunctional agriculture. Aldershot. Ashgate Pub.

OLSON, M. (1999). A lógica da acção colectiva. S. Paulo. EDUSP.

PECQUEUR, B. et ZIMMERMANN, J. (2004). Economies de proximité. Paris. Hermés.

PECQUEUR, B. (1996). Dynamiques territoriales et mutations economiques. Paris. L'Harmattan.

PEREIRA, H. et al., (Eds.) (2009). Ecossistemas e bem-estar humano: avaliação para Portugal do Millenium Ecosystem Assessment. Lisboa. Escolar Editora.

POLANYI, K. (2000). A_grande transformação, as origens da nossa época. Rio de Janeiro. Editora Campus. 9ạ edição. (1’a edição 1944).

RIFKIN, J. (2014). A Terceira Revolução Industrial: Como a nova era da informação mudou a energia, a economia e o mundo. Lisboa. Bertrand Editora. 
RIFKIN, J. (2001). A Era do Acesso._Lisboa. Editorial Presença.

ROSNAY, J. (2012). Surfer La Vie. Éditions LLL.

ROSNAY, J., PAPILLON, F. (2010). Et l'Homme créa la vie: la folle aventure des architectes et des bricoleurs du vivant. Éditions LLL.

ROSNAY, J. (2008). 2020 : Les Scénarios du Futur. Paris. Fayard.

ROSNAY, J. (2006). La révolte du Pronétariat. Paris. Fayard.

ROSNAY, J. (1995). L'homme symbiotique, regarde sur le troisième millénaire. Paris. Seuil.

SUKDEV, Pavan (2008). The report on the economics of ecosystem and biodiversity. UNEP. TEEB Group.

TEEB Report (2009). TEEB for policy-makers. UNEP. TEEB Group.

TELLES, G. R. (2011). Paisagem global, conceito para o futuro. Filosofia da Paisagem: 476-485. Lisboa. Universidade de Lisboa.

TELLES, G. R. (2003). A utopia e os pés na terra. Lisboa. Edição do Instituto dos Museus.

UNESCO (2003). Convenção para a Salvaguarda do Património Cultural Imaterial.

http://www.unesco.org/culture/ich/doc/src/00009-PT-Portugal-PDF.pdf

VIRILIO, P. (1977). Vitesse et politique, essai de dromologie. Paris. Galilée. 